\title{
Research on How to Integrate Innovation and Entrepreneurship Education into Professional Education ---Based on Empirical Analysis of Administration Management Major in Six Colleges of Guangzhou
}

\author{
Ye Haiyan ${ }^{1, a}$, Chen Qin², Chen Yaotang ${ }^{3}$, Chen Yingzhi',b,* \\ ${ }^{1}$ Software Engineering Institute of Guangzhou (SEIG), Guangzhou,China \\ ${ }^{2}$ Software Engineering Institute of Guangzhou (SEIG), Guangzhou,China \\ ${ }^{3}$ Guangzhou Yuexiu District Primary and Secondary School Students Comprehensive Practice Education Base, Guangzhou,China \\ ${ }^{4}$ Zhuji Sub-district Office of Tianhe District People's Government, Guangzhou,China
}

\begin{abstract}
The combination of innovation and entrepreneurship education with administrative management can improve professional innovation ability and development thinking of students, and improve the quality of talent training. Based on the empirical analysis of six colleges in Conghua, Guangzhou, this paper analyzed the current problems in the integration of innovation and entrepreneurship education and administrative management in universities. Combined with survey and interview data and materials, this paper studied the relationship between innovation and entrepreneurship education and administrative management from the perspectives of students and teachers, summarized and classified the integrated characteristics of the surveyed colleges. It also proposed a four-in-one "1+4" integration circle of "teacher-company-university-society", which centered on students, so as to escort the practice and guarantee of the two systems, and promote the high integration of innovation and entrepreneurship education and management majors in colleges.
\end{abstract}

\section{Background}

Entrepreneurship education is a new way of cultivating talents, gradually being regarded as a hot topic in the current reform of university education. The "Outline of the National Medium and Long-term Education Development Plan (2010-2020)" clearly stated that it is needed to actively promote entrepreneurship education in relevant universities in China. Nowadays, China's university entrepreneurship education has received extensive support from the society, including government preferential policy support, the full implementation of universities and schools and the active participation of students. According to survey, as many as 21,000 entrepreneurial activities and business forums were attended by more than 3 million students. From the perspective of the social needs of promoting entrepreneurship education, entrepreneurial talents with professional theoretical knowledge may join in the team of new entrepreneurs in the future. Integrating entrepreneurship education into the education industry can effectively help students acquire advanced entrepreneurial ideas to a certain extent. The best way for students to receive entrepreneurship education is to reform and integrate with their own majors to find the best path.
After years of research, Chinese scholars have made in-depth research on innovation and entrepreneurship education, which is still in a state of rapid development, with broad research space and development prospects, but there are still problems in research and practice. Especially in the research of undergraduate colleges, the research on the combination of innovation and entrepreneurship education and business management is still at the level of theoretical discussion. At present, colleges and universities in Conghua District of Guangzhou are in an important stage of reform and development. It is an important research topic on how to take the ride of innovation and entrepreneurship education and find the direction of transformation and development. Therefore, as for the universities in Conghua District of Guangzhou City, it is of strategic and practical significance to deeply explore the theory and practice of the integration of innovation and entrepreneurship education and administrative management.

Students who pass administrative management education can combine the textbook knowledge and practical skills of the major. Entrepreneurship education is a new teaching concept that can promote students' entrepreneurial awareness, entrepreneurial literacy and entrepreneurial skills. The purpose of entrepreneurship 
education is to obtain comprehensive talents, so that students can be equipped with knowledge about human resources, marketing and finance, and have the basic ability to start a business. Entrepreneurship education is different from administrative management majors in terms of educational concepts and content, but there is also a connection between the two, which promotes each other. Entrepreneurship education can't exist separately from administrative management. Similarly, the development of entrepreneurship training has played an active role in promoting the reform and improvement of the administrative management profession.

\section{Investigation and Analysis of the Integration of Innovation and Entrepreneurship Education and Administrative Management Majors in Colleges and Universities}

\subsection{Research Design}

Taking universities in Conghua District as an example, this article introduces the current situation of the organic combination of entrepreneurship and innovation education and administrative management universities. Through the questionnaire survey, it analyzed the cognition of the concept of curriculum integration and curriculum construction among students of different grades and genders. The subjects of this survey are mainly 6 colleges $\backslash$, namely Software Engineering Institute of Guangzhou, Zhujiang College of South China Agricultural University, Guangzhou City Polytechnic, Guangzhou Nanyang College, Nanfang College Guangzhou and GuangZhou City Construction College. Since the survey was conducted during the holidays, the number of people surveyed by each university was not even. A total of 254 valid questionnaires were collected in this survey. This survey mainly used the method of issuing questionnaires online. There were both in-depth interviews with individual subjects and discussions with multiple students. A total of 254 valid questionnaires were collected in this survey, which mainly applied the method of issuing questionnaires online. There were both in-depth interviews with individual subjects and discussions with multiple students.

\subsection{Investigation and Analysis}

\subsubsection{Analysis on the Curriculum System of the Integration of Administrative Management and Innovation and Entrepreneurship Education}

The first one is the opening of innovation and entrepreneurship courses. Researching and investigating are carried out in schools such as Software Engineering Institute of Guangzhou, Guangzhou Urban Construction Vocational College and Guangzhou Nanyang Polytechnic Vocational College, GuangZhou City Construction College and Guangzhou Nanyang College. The credits of various schools in the general education courses or elective courses that implement the "administrative management" professional talent training program in the questionnaires. The six colleges in Conghua, Guangzhou all have "administrative management" majors, with the data in the past three years have been gradually increasing. Among them, the proportion of credits related to "administrative management" in Conghua district was relatively low in 2017. From the data, it can be known that the "administrative management" credits in Conghua are less than 10 credits, as shown in Figure 1.

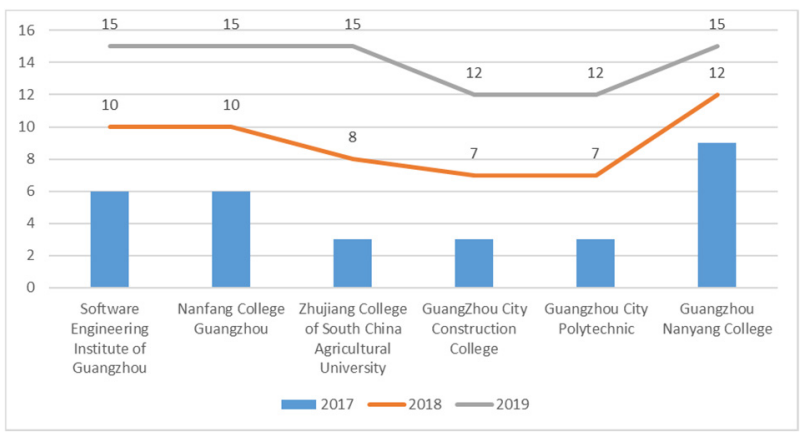

Figure 1: Credits of innovation and entrepreneurship of six colleges from 2017 to 2019

From the questionnaire of students in various schools, it can be seen that half of the colleges and universities have courses of innovation and entrepreneurship. 50\% students in colleges and universities know innovation and entrepreneurship-related courses, while $35 \%$ students don't understand, which means that colleges and universities in the Conghua, Guangzhou should also emphasize on innovation and entrepreneurship education.

The second one is whether innovation and entrepreneurship education elements should be added to professional courses. $57 \%$ of respondents said that they have participated in research on entrepreneurship and entrepreneurship education in professional courses. For example, more entrepreneurial cases are cited in the classroom, and cases of entrepreneurial failure are analyzed, but there are also some aspects that are not comprehensive.

The third one is whether to increase the proportion of innovation and entrepreneurship courses in the interprofessional courses?

At present, less than $10 \%$ (account for $7 \%$ ) of the interviewed students said that the two-innovation courses have been added to the inter-professional courses, while other students believe that the proportion of the twoinnovation courses has not been significantly increased in the inter-professional courses.

The fourth one is the proportion of corporate teachers participating in professional courses. The survey results show that $82 \%$ of the interviewed students hope that corporate mentors can give them face-to-face teaching of professional courses. They also wish to get the guidance of business mentors and share some experience with them. Among them, $70 \%$ of students believe that classroom teaching with the participation of corporate mentors will bring them greater gains. The main reason for the benefit is that students can have a clear understanding of society 
and the company in advance, and they can also have a clear goal for their career prospects and future career plans, so as to improve their shortcomings and improve themselves in many ways during the future college life.

\subsubsection{Survey of Student Groups}

The first one is the proportion of participating in innovation and entrepreneurship-related technological activities and competitions in the past five years. From the survey, it can be found that $20 \%$ of students participated in innovation and entrepreneurship activities and competitions, of which $1 \%$ of students participate in national innovation and entrepreneurship competitions, 5\% of students participate in provincial competitions, and 5\% of students participate in school competitions. Among them, $4 \%$ of students participated in two levels of activities at the same time. From the perspective of the reasons for participation, it is mainly affected by factors such as the national innovation and entrepreneurial atmosphere and environment, as well as the school's recognition and rewards. After the students received the awards, most schools gave out awards. Some schools also highlight scholarships and the selection of outstanding students, which has increased students' enthusiasm for participation. Some students think this will help them in their future entrepreneurship and employment.

The second is the proportion of professional courses and innovation and entrepreneurship courses in the current courses. $35 \%$ of the students said that the number of innovation and entrepreneurship courses in the current courses has reached a quarter, while most students believe that the number of innovation and entrepreneurship courses is still relatively small.

The third one is the knowledge of innovation and entrepreneurship received in the course of professional courses. Most students said that the innovation training they received in the innovation and entrepreneurship course was more effective and impressive. However, the knowledge input of innovation and entrepreneurship is not much in the learning process of professional courses, while students can deeply feel the application of innovation and entrepreneurship related knowledge, when they follow teachers to participate in projects and competitions.

The fourth one is whether to form an entrepreneurial team. Whether students are willing to form or participate in entrepreneurial teams reflects the impact of the integration of innovation and entrepreneurship education on students' entrepreneurial motivation and willingness to enterprising. Among the students surveyed, $30 \%$ of the students have established or participated in an entrepreneurial team, while $2 \%$ of the students have established their own entrepreneurial team.

\section{Problems in the Integration of Innovation and Entrepreneurship Education and Administrative Management}

\subsection{Problems in the Integration of Educational Concepts}

According to a survey, $52.1 \%$ of students believe that innovation and entrepreneurship education is closely related to administrative management. $36.4 \%$ of the students believe that innovation and entrepreneurship education and administrative management are related, with low correlation. $4.6 \%$ of the students believes that there is no relationship between the two, while remaining $8.9 \%$ said they did not understand the relationship between the two, as shown in Figure 2.

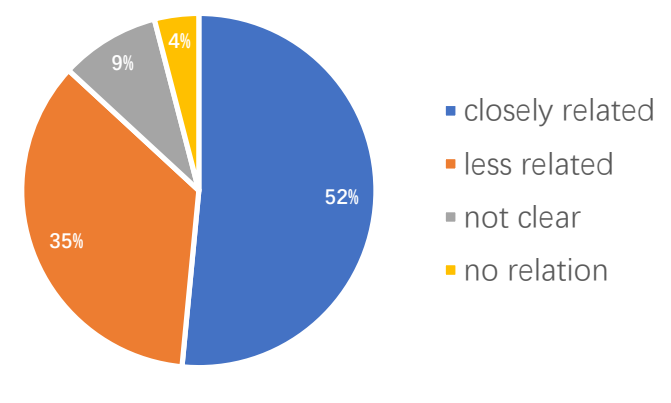

Figure 2: The distribution ratio of the relationship between innovation and entrepreneurship education and administrative management

Innovation and entrepreneurship education has achieved some successes in the current education system, which play a positive role in student employment and promotion of entrepreneurship. However, it is still too early to say that it can achieve $100 \%$ integration with the administrative management major, as students can't fully understand double innovation. Among the students who answered the questionnaire, $40.3 \%$ believed that the school provides an optional entrepreneurial education course rather than a general course which are not closely integrated with the vocational knowledge course. This reflects the fact that school innovation and entrepreneurship education in this field is not good enough, and students' understanding of employment education and other aspects is too narrow. Chinese universities mainly cultivate elites through administrative management majors. An important way to cultivate high-quality talents is to conduct administrative management education. As a new educational model, innovation and entrepreneurship education can add new educational methods to students, which guide their employment thinking, stimulate their entrepreneurial thinking, encourage them to master entrepreneurial skills and prepare for entrepreneurship. This kind of education model is a "magic key" to promote the employment of students, as innovation and entrepreneurship education and administrative management are inseparable, so as to promote each other, merge with each other and develop with each other, thereby improving the overall quality of students. 


\subsection{Low Participation of Student}

It can be seen from the survey results that students have different entrepreneurial aspirations, with the same sex, same major but different grades. For professional courses that are related to innovation and entrepreneurship knowledge, $14.1 \%$ of the number of students shows very strong interests, $34.4 \%$ of students shows very strong interests. $42.6 \%$ of students shows normal interest, while $2.6 \%$ of students shows no interest. $6.2 \%$ of the number of students have no idea, as shown in Figure 3.

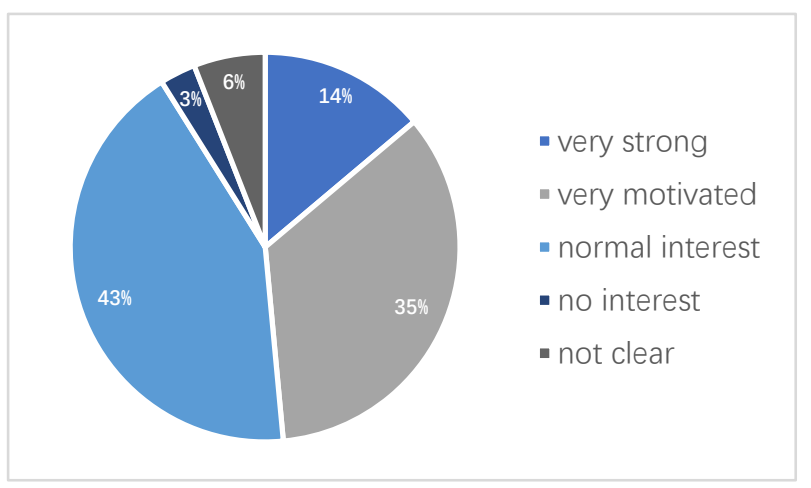

Figure 3: distribution of students' entrepreneurial willingness

The status quo of students' innovation and entrepreneurship education in schools is analyzed. Although schools encourage the combination of innovation and entrepreneurship education and the major of management, and work hard to make some measures to deepen the cooperation between the two, most students are still passive in the actual process. As the first beneficiaries of the combination of innovation and entrepreneurship education and administration majors, students' participation will obviously influence the effect of the combination of innovation and entrepreneurship education and administration majors.

\subsection{The Separation of Curriculum from the Background of Students}

Schools strive to create innovative professional courses through general education, administration and career development. In the administrative management major, schools integrate the cultivation of innovation ability and entrepreneurial quality into the knowledge modules of the professional curriculum, without adopted a targeted program or subdivided into different disciplines and different grades. The survey found that students' entrepreneurial abilities of different genders are significantly different, with girls' is significantly higher than that of boys. Through the survey of the distribution of the proportions of courses between students of the same gender and different grades, it is found that students of different grades have different requirements of double innovation courses. However, when the school advocates the combination of innovation and administration, it ignores one important thing that students of different grades have different levels of professional understanding. $67.2 \%$ of the students believe that innovation and entrepreneurship education needs to be instilled into daily vocational education and cultivated in a subtle way, which will greatly help their future independent entrepreneurship. At present, high employment pressure of students leads to many difficulties that are hart to overcome. Therefore, students at school hope to improve their understanding of the major and build a solid foundation for entrepreneurship by studying the reformed professional courses and other extracurricular knowledge of the major. However, schools did not accurately classify the problems, which obviously hindered the integrated development of innovation and entrepreneurship education and administrative management.

\subsection{Inadequate Entrepreneurship Environment and Guarantee System}

Chinese education has focused on learn knowledge from textbooks for a long period of time, thus neglecting the cultivation of students' innovative ability. Teachers will even give negative comments on some questions raised by students in the classroom, which undoubtedly obliterates the possibility of students' innovation. What's more, Chinese traditional educational concepts will also have a greater impact on the education of innovation and innovation of college students. In the traditional concept, most parents are more inclined to get a relatively stable job when their children choose employment, and don't support innovation and entrepreneurship, which undoubtedly dampens students' enthusiasm for innovation and has a certain impact on the double-creation education of college students. Meanwhile, the double-creation education requires more manpower, material resources and financial resources, while college students can't obtain financial support for their innovation and entrepreneurship projects, which makes many good projects be strangled in the cradle. In summary, it is difficult for college students to achieve a considerable result in the double-creation education.

\section{Reflection on the Promotion of the Deep Integration of College Innovation and Entrepreneurship Education and Administrative Management}

From the two perspectives of students and teachers, it analyzes the current situation of the integration of innovation and entrepreneurship education and administrative management, summarizes and sorts out the integration characteristics of the investigated universities, and proposes a student-centered and " $1+4$ " fusion circle of "teacher-enterprise-university-society", that is to say, the four levels of teachers, enterprises, universities and society, with students' learning needs as the center. From the perspective of teachers, they should give students opportunities to learn innovation and entrepreneurship courses, so that they can understand the content of innovation and entrepreneurship in the classroom. From the perspective of companies, they should allow students to practice knowledge in the companies. As for colleges and universities, schools provide college entrepreneurship 
parks for their students, at which they can apply the knowledge learned in the classroom to incubation projects. From the angle of society, they should provide financial assistance to the projects created by the students in the school.

Students can continuously hone their innovation skills and obtain multi-dimensional innovation and entrepreneurship support from the $1+4$ integration circle. We need to construct three basic systems from the three aspects of curriculum, practice and implementation guarantee. In short, the course is integrated into the dual innovation curriculum system, which is a support and guarantee system for the combination of professional education and dual innovation education. The students' work is to show the model more conveniently, as shown in Figure 4. Then, we will conduct research and analysis through this " $4+1 "$ fusion circle model, and propose the following countermeasures for the above problems.

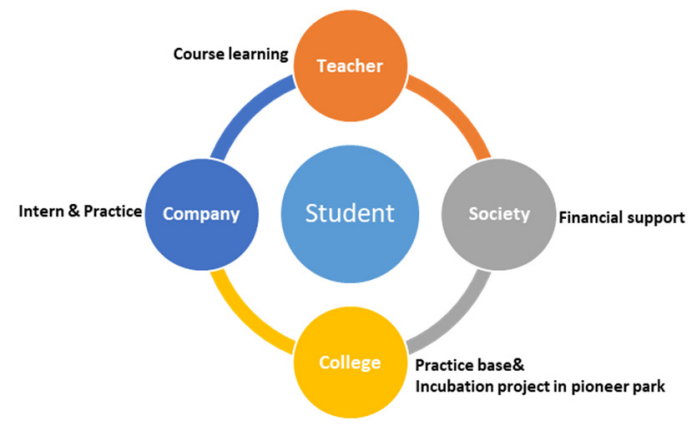

Figure 4: "4+1" fusion circle

\subsection{Strengthening the Construction of Teachers for Innovation and Entrepreneurship Education}

According to the data, some students still don't understand the important link between innovation and entrepreneurship education and administrative management. More than $2.6 \%$ of the students believe that the two are not related. With the continuous deepening of reforms, people believe that innovation and entrepreneurship education can guide students to employment and enhance students' entrepreneurial skills. Therefore, about $79 \%$ of students believe that innovation and entrepreneurship education and management are mutually integrated and reinforcing. 3.6\% of students believe that innovation and entrepreneurship education is only a small part of employment education, obviously ignoring the important value of innovation and entrepreneurship education, while $13.4 \%$ of students believe that the main form of innovation and entrepreneurship education is various entrepreneurial competitions. It is easy to see that China's promotion of innovation and entrepreneurship education is still insufficient from the above data, resulting in students paying inadequate attention to employment education.

Therefore, it is needed to improve the innovation and entrepreneurship courses of the administrative management major. On the one hand, professional teachers should improve their own level, continuously strengthen the research and exploration of professional education, seek entrepreneurial opportunities in the professional education of administrative management, and continuously improve their own innovative entrepreneurial theory and practical ability. On the other hand, it is required to cultivate the corresponding professional talents in the teaching team, with the spirit of double innovation, which means that the old concept of the past should be changed and the dual entrepreneurship education need to be integrated into the management system to help students improve their own employment level.

\subsection{Innovative Curriculum System}

Based on the integration concept, the goal to clarify educational goals is to build a new curriculum system. According to survey data feedback, same-sex students of different grades attach varies importance to courses that combine innovation and entrepreneurship education and administrative management. The new curriculum focuses on the cultivation of professional knowledge, laying a solid professional foundation for entrepreneurship. Junior students like to learn innovation and entrepreneurship knowledge through textbooks, and use this to guide their innovation and entrepreneurship learning, so as to expand their innovative thinking, while senior students not only learn the content of the course, but also use professional knowledge to guide innovative thinking. They learn the unique significance of innovation and entrepreneurship education and administrative management from the actual situation. On the one hand, it is possible to test whether students' theoretical knowledge meets the standard through practical operations. On the other hand, innovative education and entrepreneurial spirit are very practical. It is effective to cultivate innovative entrepreneurial talents, combining with professional practice. In fact, teachers should not only improve the common sense and basic innovative professional courses of all students, but also improve and reflect their own professional qualities. Each college of the university needs to form an expert group. Corresponding courses are developed according to the characteristics of each subject knowledge and the characteristics of each college, each major and each grade. It is necessary to optimize the content of the courses and integrate knowledge from multiple disciplines and different types to form a professional system and an innovative education system. According to the overall needs of students, it is needed to organically combine innovation and entrepreneurship education with business management, integrate the concepts of innovation and entrepreneurship into professional knowledge courses, and promote the penetration and integration of the two.

\subsection{Strengthening Cooperation between Secondary Colleges}

The characteristics of cultivating elite talents are complex and systematic. The characteristics of innovation and entrepreneurship education are comprehensive and practical. Therefore, the principle of applicability of the integration of the two must be followed. Colleges ensure 
the smooth progress of its administrative management major, and at the same time strengthens the cooperation between academics by strengthening the exchanges between the colleges. The organic combination of innovation and entrepreneurship education and administrative management needs to be realized from the following aspects. The first is the training goal, the second is the credit requirements and the third is the practical education activities. The effective integration of the two can help improve the overall quality of students and continuously improve employment. In order to strengthen the interdisciplinary training of "double innovation" talents, innovative and entrepreneurial talents should not only have solid professional knowledge, but also have interdisciplinary knowledge and broad disciplinary vision. In order to respect the differences of various disciplines, it can also be closely linked to entrepreneurship education according to professional categories, such as humanities and natural sciences. Universities need to encourage interdisciplinary learning. In order to establish a relatively complete training system, it is needed to organize more related majors, enrich and diversify the curriculum, and increase a large number of research topics. According to the characteristics of each professional discipline, it is required to analyze and respect the differences, increase tolerance, so as to meet students' different needs for innovation and entrepreneurship education, greatly improve the fit of innovation and entrepreneurship education and cultivate comprehensive talents.

\subsection{Improvement of Teaching Methods}

It optimizes the relationship between theoretical education and practical education, and organically integrates the traditional administrative professional practice platform with the innovation and entrepreneurship training platform. Research shows that there still exist problems in developing innovative professional courses in universities. The teacher's teaching method is still limited to the classroom, with only one teaching method, which is also the main reason hindering the development of new courses. The comprehensive deepening of the classroom teaching reform has enabled the first and second classrooms to organically implement the classroom teaching reform, promote teacher-student interaction and promote the development of innovative thinking. The new classroom indicator test does not always have standard answers, nor does it require 60 points to pass. Colleges and universities should actively innovate and encourage students to study independently and think independently by adding subjective questions, and to allow students to choose their major within a certain range. Heuristic and collaborative education are provided. Professional teachers will integrate cutting-edge academic development and the latest research results into classroom education.

\section{Conclusion}

Due to the university's focus on innovation and entrepreneurship education, this education has gradually become a primary way to strengthen professional knowledge and promote practical ability in recent years. As we all know, the university's measure of combining innovation and entrepreneurship education with administrative management has a positive meaning for the development of students' personal abilities and the impact on society. However, the current university's understanding of innovation and entrepreneurship education is obviously not enough. The effectiveness of the curriculum has yet to be investigated, and the current integration effect between the two is not outstanding enough, as the curriculum is out of touch with the professional development of students. Starting from the teaching process, through the organic combination of innovation and entrepreneurship education and administrative management, students can not only learn to consolidate their professional knowledge, but also cultivate their innovative spirit and entrepreneurial ability. At the same time, it can guide them to establish the correct professional development direction and deepen their love for this major.

In the implementation of innovation and entrepreneurship education courses and educational management, universities have consciously created conditions to achieve in-depth integration of innovation and entrepreneurship education and management, including the optimization and management of the educational environment. For example, the optimization of the structure of teaching staff, introduction of suitable amount of practical teachers from outside the school, and the increase of the implementation of practical courses. Actively changing curriculum management and curriculum implementation methods to fully stimulate students' internal motivation for self-learning, establishing an incubation platform for students' innovation and entrepreneurship, enriching resources, and establishing communities of practice all methods to provide continuous guidance and long-term support for the growth of students. It is of significance to carry out research on the subject of the organic integration of innovation and entrepreneurship education and administrative management. Since the scope of this research only covers one university, which is not universal. Besides, the combination of innovation and entrepreneurship education and administrative management is still in its infancy, with the effect of the integration not been observed and verified. This is a shortcoming of this research, and also a point where it can be optimized and improved in the following research.

\section{Project funding}

1. The "Thirteenth Five-Year Plan" of the Guangdong Higher Education Association's 2020 annual higher education research special project youth project "Research on the Integration of Innovation and Entrepreneurship Education and Professional Education in Colleges and Universities" (20GQN27). 2. "Research on the Integration of Innovation and Entrepreneurship Education and Professional Education in Colleges and Universities" (ky202052), the teaching, research and teaching reform project of Software Engineering Institute of Guangzhou.3."Innovation and innovation from the 
perspective of school-government cooperation Research on the Training Mode of Industry Talents "(DJSZ202120) Party building and ideological and political education project of Software Engineering Institute of Guangzhou.

\section{Reference}

1. Xiufang Qian, Huamei Shi, Chunpeng Ge, Honghui Fan, Xiaorong Zhao, Yijun Liu, Application Research on Service Innovation and Entrepreneurship Education in University Libraries and Archives [J], International Journal of Computational Science and Engineering, 2020,22(1);

2. Yuanyuan Sun, Research on the Necessity of Innovation and Entrepreneurship Education in Local Universities [J], Academic Journal of Humanities \& Social Sciences, 2019,2(7);

3. Ping Zhao, Jiaonan Li, Xiaoyan Zhang. Research on the Interactive Development of Innovation and Entrepreneurship Education and Tourism Specialty Education in the Context of Cultural and Tourism Integration: A Case Study on the Production of Ubiquitous Learning Space in YXHMC [A]. Wuhan Zhicheng Times Cultural Development Co. Ltd., Proceedings of $2^{\text {nd }}$ International Workshop on Education Reform and Social Sciences (ERSS 2019) [C]. Wuhan Zhicheng Times Cultural Development Co. Ltd., 2019:9;

4. Wang $\mathrm{Xi}$, Research on the Integration Path of University Innovation and Entrepreneurship Education and Administrative Management [D], Hebei University, 2019;

5. Phoebe Anne M. Banez, Chona Y. Co, Kristine M. Falconitin, Felipe E. Balaria, Jennifer G. Fronda. From Theory to Practice: The Experience of Sichuan Tourism University on Integrating Professional
Education with Innovation and Entrepreneurship Education [J]. Indian Journal of Public Health Research \& Development, 2019,1(1);

6. Guozhong LI, Zhangming ZHOU, Xiaolong MA. The Exploration of Mechanisms of the Innovation and Entrepreneurship Education in Colleges and Universities Guided by Party Construction [J]. CREATIVITY AND INNOVATION, 2019,3(1);

7. Yao Xiaoling, Zhang Yating. Investigation on the Innovation and Entrepreneurship Education Ecosystem of Stanford University [J], Journal of Shanxi University (Philosophy and Social Sciences Edition), 2018,41(05):122-127;

8. Wu Tong, The Construction of Enterprise Human Resource Recruitment System in the Era of Big Data_Based on the Perspective of Competency Model [J], Chinese Business, 2018(24):9-11;

9. Chang Chengxia, Research on the Integration of Quality Education and Innovation and Entrepreneurship Education in Universities of Science and Engineering in China [J], Teacher Education and Curriculum Studies, 2018,3(1).

10. Zhang Tingting, Zhang Bo, Research on the Integrated Development of College Students' Innovation and Entrepreneurship Education and Administrative Management Majors in Newly-built Applied Undergraduate Colleges [J], Financial Theory and Teaching, 2018(01):107-109; Researches in Library Science, 2016(03): 2-6+57;

11. Xue Lei, Research on the Development of Entrepreneurship Education in Colleges and Universities—Based on the Perspective of the Integration of Entrepreneurship Education and Administrative Management [J], Economic Perspective (First Issue), 2014(12): 80-82. 